\title{
Engineering and Engaged Scholarship at Penn State Part II: The Existing Ecosystem
}

\author{
Thomas Colledge, $\mathrm{PhD}, \mathrm{PE}$ \\ Penn State University \\ University Park, PA 16802 \\ thc100@psu.edu
}

Contributing authors:
Dr. David Riley
Dr. Susannah Barsom
Dr. Karen Thole
Dr. Michael Alley
Dr. Rachel A. Brennan, PE
Melissa Marshall
Christine Haas
Elizabeth Kisenwether
Andrew M. (Mike) Erdman
Khanjan Mehta
Joshua Kessler
Krista Liguori

Abstract - The objective of engineering education is to educate students who are 'ready to engineer'. This implies that students should be broadly prepared with not only deep knowledge and understanding of the technical fundamentals, but also the pre-professional skills required to be successful in the engineering workplace of today and tomorrow ${ }^{1}$. Part I of this paper includes a brief rationale and need for 'Engaged Scholarship' and the inherent need for a robust ecosystem to support it. Part II details the existing curricular, co-curricular, and extra-curricular efforts which form the core for the engaged scholarship ecosystem in the College of Engineering at the Pennsylvania State University. Curricular, co-curricular and extra-curricular opportunities for students are detailed. Part III provides an overview of how this assortment of minors, certificates, programs, courses, and student organizations is being integrated and institutionalized into a strategic mission for the University.

Index: engaged scholarship, service learning, educational ecosystem

\section{Current Penn State Ecosystem}

Figure 2 contains an illustration of various minors, certificates, programs, courses and student organizations that constitute the academic components of the engaged scholarship 'ecosystem' at Penn State (University Park). As illustrated by the graphic, there are quite a number of distinct efforts. There is, however, no generic framework available which describes how all of these activities combine in a self-sustaining, optimal fashion. A successful framework would allow all parties to achieve independent goals in a complementary community context, providing resources and opportunities to all parties resulting in net benefits ${ }^{60}$.

Beyond the students who pursue the Engineering and Community Engagement Certificate and dovetail those credits into one of the minors, or the HESE students who publish in the International Journal for Service Learning in Engineering, Humanitarian Engineering and Social Entrepreneurship (IJSLE), or the Learning Factory to incorporate Capstone Design courses, there are few formal, institutionalized pathways and collaborations which nurture interaction among and between all of these entities.

It is important to recognize that in addition to the academic components of the ecosystem at Penn State, there are numerous entities internal to Penn State which act to facilitate or collaborate with these academic undertakings. Table 7 lists some of these support resources. 
Some of these support resources are more relevant and of value to the academic efforts than others - depending on the type of project, its location, and specific requirements. Quite often, the recognition of these support resources and the resulting collaborations depend upon the faculty champion and his/her networking abilities rather than benefiting from a formal, institutionalized framework.

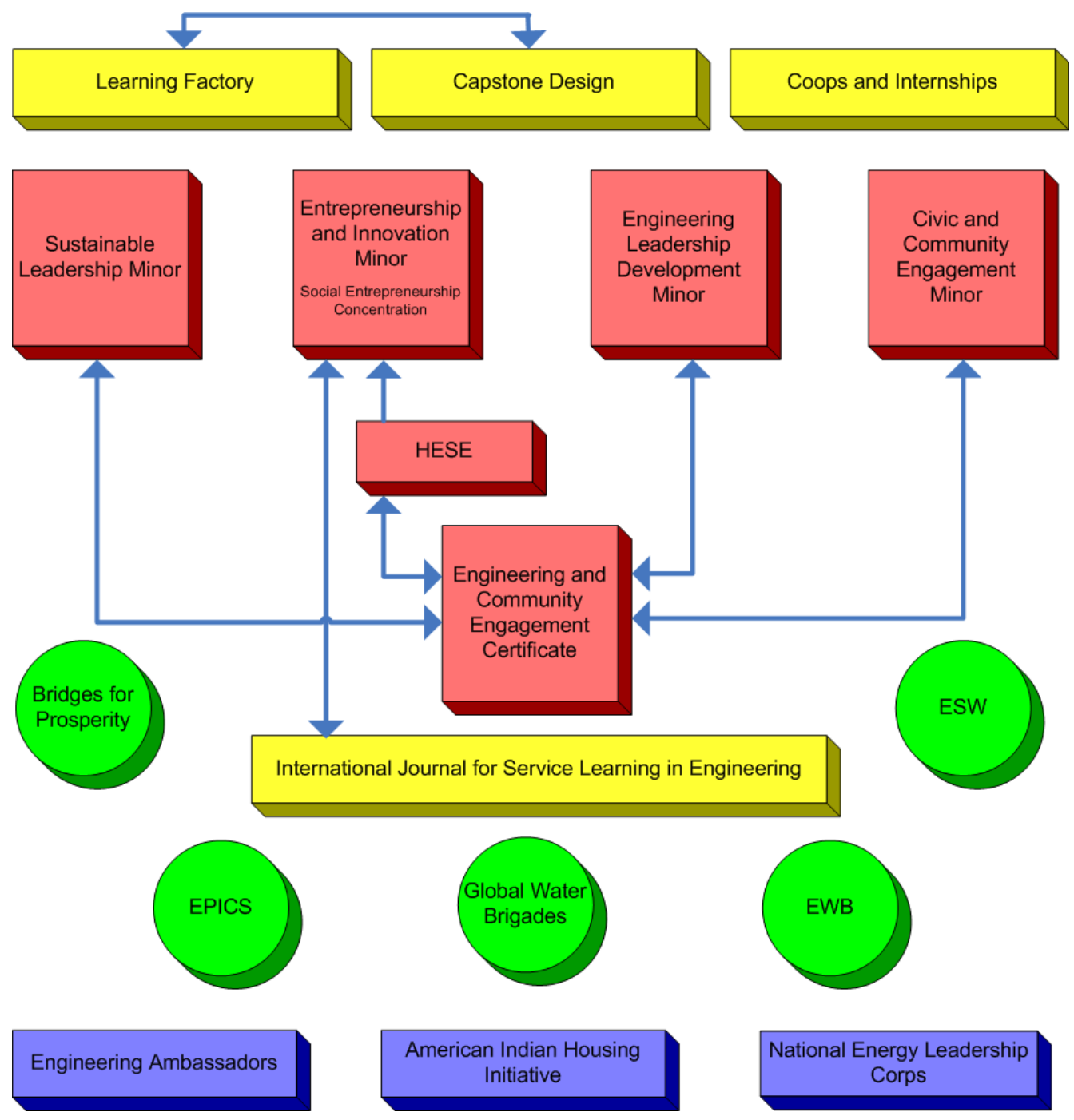

FIGURE 2

Current Penn State EngineERING 'Engaged ScholarshiP' ACADEMic ECOSYSTEM MaP

(EACH EFFORT SHOWN IS INDEPENDENT. ARROWS ARE INTENDED TO INDICATE POSSIBLE PATHWAYS) 
TABLE 7

ENGINEERING AND ENGAGED SCHOLARSHIP COLLABORATORS AND SUPPORT RESOURCES

\begin{tabular}{|l|l|}
\hline - Global Penn State & - Global Engineering Education \\
\hline - Africana Research Center & - Shreyer Honor College \\
\hline $\begin{array}{l}\text { - Inter-institutional Consortium for Indigenous } \\
\text { Knowledge }\end{array}$ & $\begin{array}{l}\text { - Leonhard Center for Advancement of } \\
\text { Engineering Education }\end{array}$ \\
\hline - Center for Science and the Schools & - Risk Management \\
\hline $\begin{array}{l}\text { - Dickinson School of Law, International } \\
\text { Sustainable Development Projects Clinic }\end{array}$ & $\begin{array}{l}\text { - Tourism Research Lab, College of Health and } \\
\text { Human Development }\end{array}$ \\
\hline - COE Internships and Cooperative Education & - Office of Engineering Diversity \\
\hline - Rock Ethics Institute & - Center for Sustainability \\
\hline - Alliance for Education, Science, Engineering and \\
\begin{tabular}{l} 
Development in Africa \\
\hline - Penn State Milton S. Hershey Medical Center
\end{tabular} & - Farrell Center for Corporate Innovation and \\
\hline
\end{tabular}

Each of the curricular, co-curricular, and extra-curricular efforts at Penn State will be described below. Following the descriptions of each of the academic components, Part III of the paper will provide a description of the journey being undertaken by Penn State to integrate these various academic efforts, with the support resources, into a sustainable, university-supported ecosystem - capturing the benefits inherent in such pedagogy while making the entire effort sustainable at the institutional level.

\title{
CURRICULAR EFFORTS
}

\section{Engineering Leadership Development Minor (ELDM)}

\author{
Andrew M. (Mike) Erdman, Director
}

\section{Introduction}

The Engineering Leadership Development program at Penn State stands as one of the first such programs created at a university level, and enjoys 20 years of practice, producing over 600 graduates with a full minor in leadership development, and approximately twice that number who have participated in some of the courses in the minor. The educational experience is heavily based on experiential learning, with a firm belief that hands-on experience not only helps in understanding, but in retention of the material covered in courses.

\section{Background}

The Penn State program began as an initiative of the Leonhard Center for Engineering Education Excellence in 1994. At the time of its formation, the program focus was on expanding the technical education of our engineers to include professional skills, such as team-work and communications. Approximately 10 years into the program, Penn State recognized the need to extend the scope of the program to include global awareness and cross-cultural skill training. Today, the program includes many project teams where the principles of leadership and teamwork may be exercised, and most of these projects focus on engineering solutions to crucial food, water and employment needs in developing countries. International teaming with other 
universities, such as Corvinus (Hungary), Taibah (Saudi Arabia), Abomey Calavi (Benin), and KU Leuvin (Belgium) are augmented by optional student travel to Europe and Africa. These virtual teams have worked on projects ranging from improving agricultural practices in Peru, to small start-up businesses in Haiti, home heating in Roma communities in Hungary and efficient, clean processing of food in Africa.

Figure 3 presents a graphical display of the 18 credit minor with core leadership courses identified. If thoughtfully chosen, to provide both a stretch as well as skills useful in a future leadership position, the 6 elective credits may be used for both the student's major as well as the leadership minor.

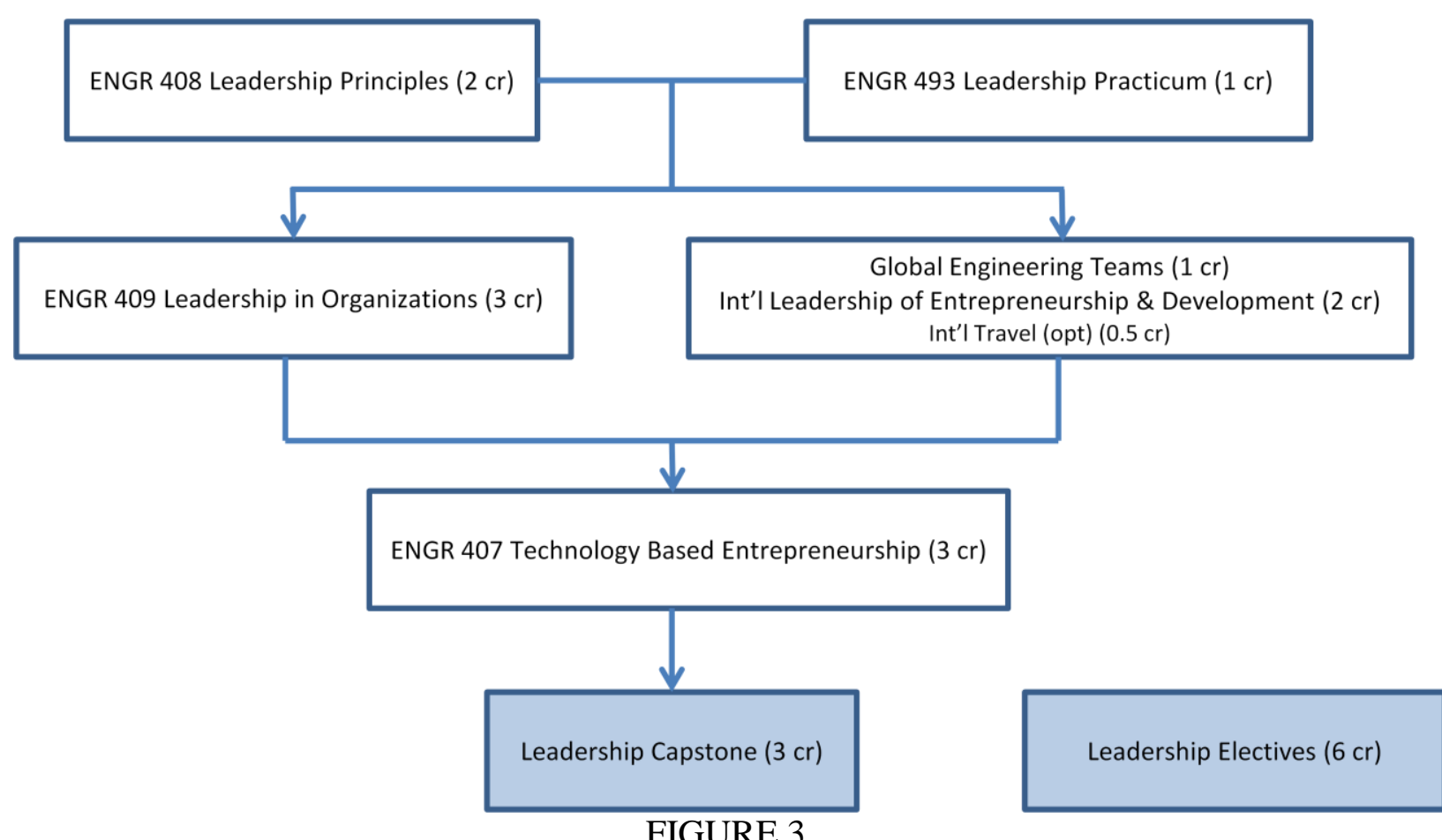

OVERVIEW OF PENN STATE ENGINEERING LEADERSHIP DEVELOPMENT MINOR CURRICULUM (BLUE INDICATES OVERLAP WITH CERTIFICATE REQUIREMENTS)

\section{Outcomes}

The leadership program at Penn State has performed several studies of the efficacy of our curriculum. Schuhmann \& Erdman ("Learning Expectations and Outcomes for an Engineering Leadership Principles Class", ASEE, 7/13) documented the results of an assessment of the gateway courses for the minor and found significant improvement in student understanding of and performance to a number of fundamental leadership principles. Findings included increases in understanding of ethical issues, global considerations, self knowledge and teamwork. Additionally, Gordon, et.al. ("Cultural Accommodation in Virtual Engineering Academic Teams", ASEE, 7/14) assessed how well international virtual teaming among students improved their outlook on cross-cultural teams. A sample finding was that teams from three different cultures/countries all felt a lower need to participate in cohesive, supportive (local) teams and were more likely to work in cross-culture teams after the virtual team experience. More recently a study (to be published) of each of the core courses in the minor showed the improvement in leadership skills as identified by the students in the courses. One example of the results was that 
on a Likert scale of 1 to 5, improvement in verbal communication was rated 4.9 as the result of the exercises conducted in the leadership principles class $(\mathrm{N}=72)$.

Further, the impact of our programs on the communities has been identified by the beneficiaries of the student projects. Local energy efficiency projects have benefited the State College Women's Shelter, the Alpha Fire Station, and the Village at Penn State (retirement home). All were received with tremendous gratitude. Perhaps more significant are the engineering solutions to increase quality and productivity provided to farms, co-operatives and start-up businesses in Peru, Haiti, Senegal, The Gambia, Benin, Ghana, Kenya and Madagascar. Machines were developed to improve, among others, the processing of highly nutritious moringa and baobab food stuff. Responses from the local users have been uniformly positive, with some achieving coveted certifications allowing for export, and government entities asking for us to extend the reach throughout the country.

\section{Lessons Learned}

The value of leadership training for engineering students cannot be overstated. At a time in our national and global economic development, having technically trained leadership help to establish the direction for the future and to provide the guidance to achieve these visions is pivotal. The Penn State program has historically produced about 40 undergraduates with the full minor and approximately twice that number of other students who have benefitted from the courses. The key shortcoming of the program is its reach. Penn State's College of Engineering now attracts nearly 2000 students annually, and the need is much greater than the capacity of the program. As a result, we are instituting a number of changes:

- A graduate program is being developed, a Master of Engineering Leadership and Intrapreneurship. The program is being developed under the scrutiny of an advisory board with representatives of the industrial partners who are most likely to benefit from such a program, including GE, GM, GKN, Merck, Rockwell Automation.

- We are growing the size of the undergraduate minor program by $100 \%$. In the spring of 2015 , we will have two sections of the Leadership Principles class, the gateway to the program.

- We are developing a video program to enable fundamental training in personal and teamwork skills that can be used by all of the freshmen seminar instructors to help prepare the incoming freshmen for the challenges of academic teamwork and carry over into their careers.

- We are developing a certificate program at both the undergraduate and graduate level to enable students who cannot afford a full minor or master degree focused on leadership to achieve quality training in leadership.

- We will be putting our core undergraduate and graduate leadership programs on-line to enable distance learning, including earning both certificates as well as the undergrad minor and graduate Master degree.

\section{Best Practices}

Perhaps the best way to summarize the best practices is to view videos associated with the Penn State Engineering Leadership Development Program.

- Click here to see how the Penn State Engineering Leadership program has influenced current students and recent graduates - current students and recent graduates discuss how the program has affected their lives and perspectives, both as engineers, and future leaders. 
- Click here to see how our Penn State leaders envision the influence of our program on student careers - the President of the University, Dean of Engineering, and program director among others reflect on how the training afforded as part of the leadership program differentiate potential employees, better preparing them for careers in today's global economy.

- Click here to see how a student outreach project benefits communities in Africa - one typical project, the baobab fruit pulp processor is delivered to the Rural Development Institute, in The Gambia.

\title{
Intercollege Minor in Entrepreneurship and Innovation (ENTI)
}

\author{
Elizabeth Kisenwether, Director
}

\section{Introduction}

The Inter-college Minor in Entrepreneurship and Innovation (ENTI) was added to Penn State's list of minors starting Fall semester 2014. The ENTI minor helps students to become innovation leaders, developing entrepreneurial mindsets, and being agents of positive change. ENTI students develop the skills and knowledge to deliver products and services to meet market needs, address significant problems and deliver solutions. ENTI Minor students come from all disciplines including the arts, business, engineering, science, agriculture, healthcare, and education. ENTI courses develop skills in creative problem solving, opportunity recognition, leadership, communication, business acumen and an appreciation for learning from failure. The ENTI education pedagogy includes experiential and problem-based learning in the classroom and outof-classroom interactions with the people who have the problems, needs or pains that spark the desire in students to find solutions.

\section{Background \&History}

Penn State's undergraduate entrepreneurship courses were started in the 1990's with courses like Technology-Based Entrepreneurship (ENGR407) and Small Business Management (BA250). The 18 credit Engineering Entrepreneurship Minor (E-SHIP) was established around new courses developed during a General Electric Fund grant starting in 2000. The E-SHIP Minor has served students from any major, with $60 \%$ being engineering majors, $25 \%$ business majors and $15 \%$ from other majors. However, starting around 2006, it became clear that students from across Penn State were interested in different concentration areas in innovation and entrepreneurship, such as food-focused needs, software applications to meet specific problems, and challenges in under-served communities around the world. The need to evolve the E-SHIP Minor was the driving force behind development of the new ENTI minor, which has a scalable structure. See Figure 4. First, there are 3 core courses in foundational knowledge and skills for all students, totaling 9 credits. Second, to complete the minor, students pick one of 7 concentration or "cluster" options for an additional 9-10 credits:
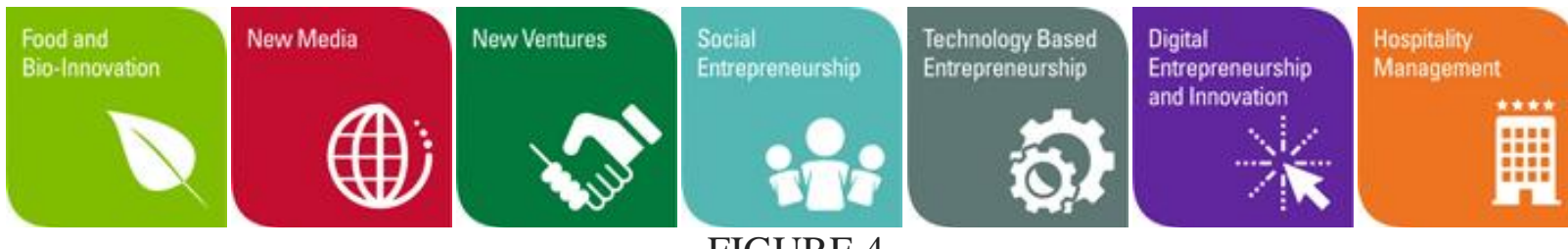

FIGURE 4

ENTI MINOR CONCENTRATIONS 
What makes the ENTI Minor different than other community engagement programs is empowering students to be change agents in new products, services or processes. Students taking the minor look for problems, needs and pains that people, organizations and communities face. Students then engage with these constituents to fully comprehend the problems, needs or pains, and begin researching possible solutions. In the ENTI Minor, emphasis is on the solution being able to create value. Value is seen as a much broader concept that monetary value. Products, services or processes that create any of the following benefits can have high value and impact: save time, save lives, create happiness, improve health, reduce hassle, save money, end bias, support equity, or right a wrong. In the ENTI minor, students work to develop solutions that deliver value, and determine a way to make the solutions sustainable across time from the business prospective, either in existing or new organizations. ENTI students work on non-profit and for-profit venture concepts. This value creation and sustainable solution work is what makes the ENTI Minor different than some of the other community engagement programs.

\section{Assessment}

Since Fall 2013, the ENTI minor has been piloting an assessment effort to measure if the students' knowledge, skills and attitudes are changing across time while taking ENTI courses. Doing pre-post surveys in courses, students have shown statistically significant changes in the following areas:

- Evaluating themselves to be more creative than peers not in entrepreneurship courses

- Having higher confidence in their ability to build value using resources not fully under one's own control

- Having higher confidence in their ability to reach decisions on complex, often conflicting, sets of data

Starting in Spring 2015, the assessment tool is being revised to shorten the length and to better analyze the students' growth in entrepreneurship and innovation knowledge, skills and attitudes (KSAs). In addition, qualitative assessments will be added, and the collection of in-class artifacts to study changes in KSAs will be expanded.

\section{Lessons Learned}

As mentioned earlier, the ENTI Minor evolved out of the E-SHIP Minor, and both programs have been based on problem-based learning. Three lessons learned are listed below, based on experiences in both the E-SHIP and ENTI Minors.

Lesson \#1: Mentoring is key. Faculty, local innovators and entrepreneurs, alumni and organizations like New Leaf Initiative (www.newleafinitiative.org) are key to students' success.

Lesson \#2: Sweat equity can take a student team far, but funding is needed to get a solution launched. Sweat equity is the unpaid, but very real, time invested in launching any new product, service or process concept and is clear proof of a person's passion to create change. However, at some point, materials must be purchased or travel must happen, and cash is required.

Lesson \#3: Foster all student ideas that are backed by passion to make a difference. Few new product, service or process concepts start out being feasible; it takes time with potential users to 
ensure the problem, need or pain is fully understood and the prototypes are actually delivering a valuable solution.

Several changes will be coming in 2015. First, the E-SHIP minor will be phased out over the next two years, and all students will be taking the ENTI Minor. The Technology-Based Entrepreneurship cluster is very similar in course requirements to the E-SHIP Minor. Second, the number of clusters in the ENTI Minor will be increasing beyond seven, with colleges not currently offering a cluster being added to the ENTI Minor. Finally, one of the ENTI core courses (ENGR310 - Entrepreneurial leadership) is being converted to an online course, and will be offered on-line for the first time in Fall 2015.

\section{Case Studies}

Below are two student start-ups, founded by E-SHIP students, to demonstrate the desired actionorientation for students.

SmartPurse, founded by Nicole Kelner (Advertising Major/ College of Communication). Nicole started SmartPurse as a first-year student, with the goal to solve a problem she, and thousands of other women experience: misplacing or loosing your smart phone because you must remove it your purse to use. Smartphone loss means huge hassle, lost property and potentially lost personal information. Nicole designed, prototyped, manufactured and sold hundreds of SmartPurses, which allows full use of the smartphone through a clear plastic window in the purse. As Nicole approaches graduation, she wants to transfer the SmartPurse brand and product line to another entity, with the goal to have the purses manufactured by womens' sewing co-ops to create jobs and to maintain product innovation. See http://smartpurse.myshopify.com/

GreenTowers, founded by Penn State engineering alumni Jared Yarnall-Schane, Dustin Betz, and Mike Zaengle (Architecture Major, College of Arts and Architecture). GreenTowers was started in 2012 as an undergraduate research project, with the goal to reconnect people to nature and to their food. By incorporating natural designs into our everyday built environment, GreenTowers creates atmospheres that uplift, inspire, and rejuvenate. With awards from the MNE (Mechanical and Nuclear Engineering) Innovation Challenge and the AG Springboard Contest in College of Agriculture Sciences, the team has been developing products such as Living Furniture, Rotating Living Wall and an indoor beehive. In addition to standard product lines, Green Towers does custom design work for companies and nursing homes to bring urban agriculture into everyday life. See http://www.greentowersusa.com/

Other student ventures which also deserve mention:

- Ruffed Outdoors - designing camouflage cloth patterns that mimic nature. http://www.ruffedoutdoors.com/

- Solid Dynamics - rapid prototyping service that utilizes the latest techniques in additive manufacturing to design and produce quality products. https://www.facebook.com/soliddynamics

- Apparatus-X - designing, building and deploying a trailer system for disaster relief services. http://www.apparatus-X.com/

- Resume Ruby - helping students write resumes that win jobs. http://onwardstate.com/2014/09/16/penn-state-students-unveil-resume-building-website/ 


\title{
Conclusions
}

The ENTI minor is one of many organizations at Penn State and in the State College area which are fostering innovation and entrepreneurial activity that engages the community and enriches education. Students involved in any of the other Penn State College of Engineering programs that impact communities - including Engineers Without Borders, Engineers for a Sustainable World, Water Bridges and Bridges for Humanity - are welcome to take courses in the ENTI minor if they are interested in determining how to make their solutions become products or processes to have broad, sustained impact.

\section{Humanitarian Engineering and Social Entrepreneurship (HESE) Program}

\author{
Khanjan Mehta, Director
}

\section{Introduction}

The Humanitarian Engineering and Social Entrepreneurship (HESE) Program engages students and faculty across Penn State in the rigorous research, design, field-testing, and launch of technology-based social enterprises. HESE ventures are multi-year endeavors in developing countries that range from low-cost greenhouses and solar food dryers to telemedicine systems and ruggedized biomedical devices. Multidisciplinary student and faculty teams work with diverse partners to develop innovative technologies and transform them into sustainable and scalable ventures that enable and accelerate positive social change. Sustainability, in this context, refers to the notion that solutions must be technologically appropriate, socially acceptable, environmentally benign, and economically sustainable. HESE courses integrate learning, research and engagement to educate globally-engaged problem solvers and prepare them for emergent careers in social innovation and international development. The program website can be accessed here, a two-minute video clip is here, and scholarly publications can be found here.

\section{HESE Curriculum}

Course offerings include Social Entrepreneurship [3 credits], Projects in Humanitarian Engineering [2 credits], Design for Developing Communities [1 credit], HESE Fieldwork Experience [0.5 credit], and HESE Reflection and Research Dissemination [3 credits]. HESE ventures are completely embedded in a series of five courses that collectively form a certificate in Engineering and Community Engagement. (Figure 5).

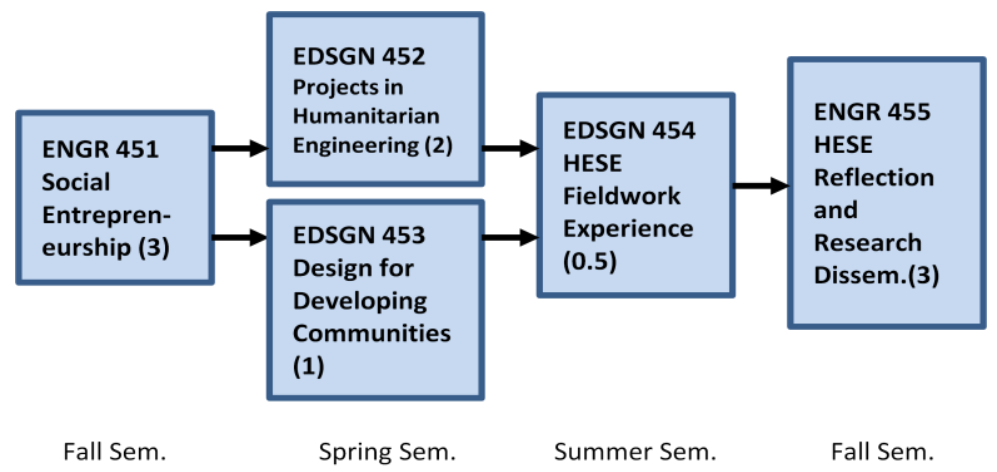

FIGURE 5

HESE COURSEWORK REQUIRED FOR ENGINEERING AND COMMUNITY ENGAGEMENT CERTIFICATE (BLUE INDICATES OVERLAP WITH CERTIFICATE REQUIREMENTS) 
It is also possible for students to use their HESE coursework, when combined with other foundational courses, to obtain a minor in Entrepreneurship and Innovation with a specialization in Social Entrepreneurship as shown in Figure 6.

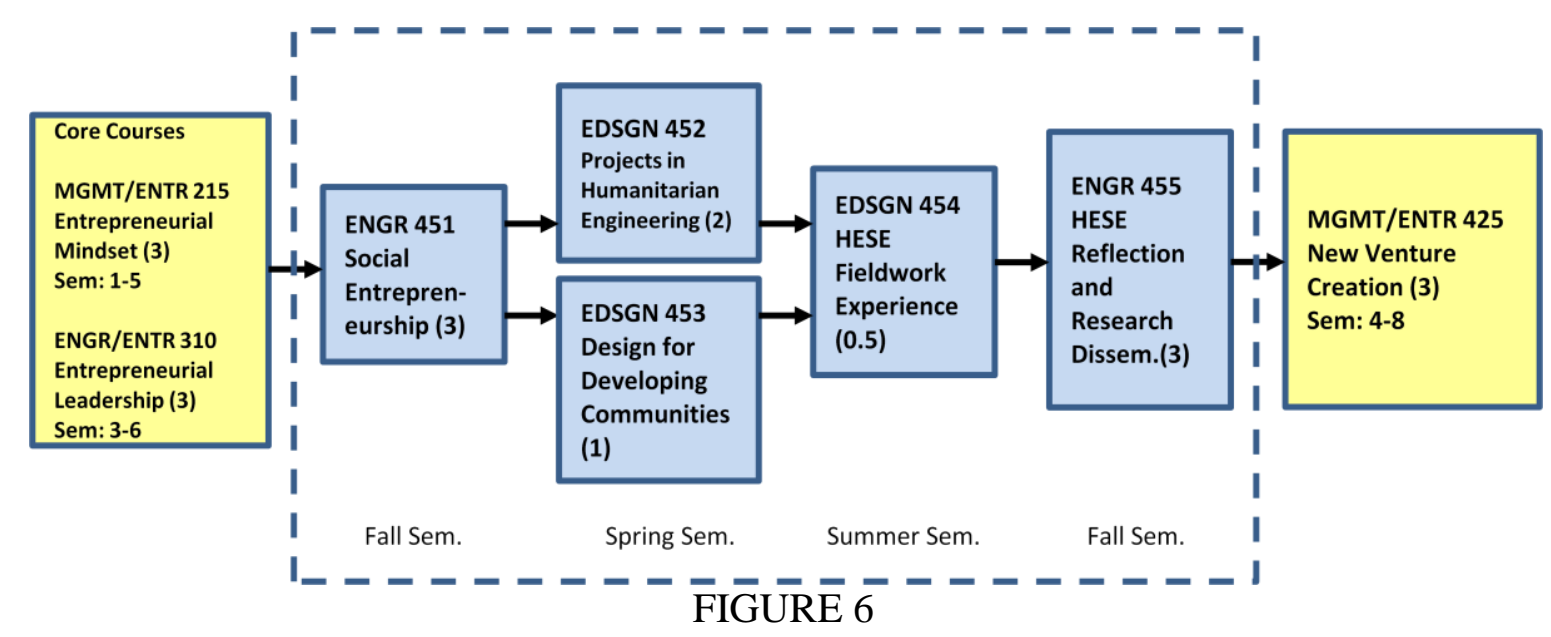

HESE COURSEWORK REQUIRED FOR MINOR IN ENTREPRENEURSHIP AND INNOVATION MINOR (WITH A SPECIALIZATION IN SOCIAL ENTREPRENEURSHIP)

The programmatic learning outcomes for students encompass knowledge and competencies in Human-Centered Design, Context-Driven Design, Social Entrepreneurship, Global Engagement, Systems Thinking, Ethical Reflection, Multidisciplinary Teamwork, Communication, and Scholarly Research and Publication.

\section{HESE Ventures}

Students travel to partnering communities to advance their ventures. Empathy, equity and ecosystems are the cornerstones of entrepreneurial engagement. Subject matter experts as well as local partners advise the venture and research teams. HESE has developed long-term relationships with communities, industry, government, non-profit, faith-based and UN partners in Kenya, Rwanda, Tanzania, India, Cameroon, Sierra Leone, Mozambique and other countries. Projects emerge from, and are supported by, these strong relationships that have been nurtured over several years. HESE ventures span several domains with most recent ventures focusing on food security and global health. The genesis of most projects can be traced back to requests made by partners in developing countries. However, rather than striving to solve the partners' specific problem(s), the HESE approach is to co-create products and services with diverse stakeholders and commercialize them to benefit larger populations. Ideas, presentations and prototypes don't solve problems; the real challenge is implementation, assessment and fast-paced pivoting. The challenge is execution - getting the job done - launching and sustaining social ventures. This focus on execution and sustainable impact drives the courses, pedagogies and operations of the HESE program.

\section{Program Impacts}

Over the past decade, HESE ventures, led primarily by undergraduate students, have collectively impacted the lives of a few million people across Kenya, Tanzania, Rwanda, India, U.S., Jamaica, Cameroon, and other countries. Some ventures have failed while others are on the 
slow but steady path towards sustainable existence and scaling up to become multi-million smile enterprises. Basic infrastructure projects like community-scale anaerobic digesters, bridges, and computer learning centers are valuable in their own right but difficult to replicate and scale. One of the first entrepreneurial successes was an affordable windmill-based hybrid power system for rural Kenya developed and implemented by our team in 2007. The UN Industrial Development Office (UNIDO) collaborated and picked up on the technology and business model. They subsequently launched the "Lighting Up Kenya" initiative that built 12 energy kiosks around the country and is scaling up to build more such kiosks now. These kiosks have collectively impacted the lives of a few million Kenyans.

Using relatively simple yet innovative technology, Mashavu: Networked Health Solutions sends a customer's medical history and vitals to a doctor, thus completing a consultation process which would otherwise involve up to two days of travel and hospital wait in less than twenty minutes. Our team partnered with former street-dwelling youth at the Children and Youth Empowerment Center (CYEC), UN Industrial Development Office, the Kenyan Ministry of Health, and other entities to develop and field-test low-cost ruggedized biomedical devices that can survive the harsh environment. After testing and iterating eight different business models, we finally arrived at a profitable model that provides full-time jobs to seven individuals, while meeting rural health challenges. These Mashavu Health Workers (MHWs) independently decide their operations, pricing, work area, and future strategy, embodying the empathy, equity and ecosystems that form the bedrock of our engagement.

Greenhouses can help farmers increase their yields and improve their livelihoods while reducing spoilage and furthering food security. Imported greenhouses sold in East Africa are too expensive $(\$ 2,500)$ for small-scale farmers. Over the last six years, our team collaborated with diverse partners to design, prototype, and field-test affordable (\$600) greenhouses for small agroenterprises and sustenance farmers. The farmers' return on investment is 4-6 months. This technology has been formally licensed to for-profit companies in Kenya (Mavuuno Greenhouses Ltd.) and Cameroon (The Greenhouse Center). HESE teams worked with these startups to set up manufacturing facilities, train employees, forge partnerships with banks and microfinance institutions, establish supply chains, and develop marketing materials. In collaboration with a non-profit, and with support from a USAID grant, similar greenhouse ventures have been launched in Sierra Leone and Mozambique. Operations are underway to jumpstart similar ventures in India, Egypt and Zambia. These independent enterprises run by local entrepreneurs deliver social impact without relying on donations and foreign aid. These are just a few examples of scalable ventures from the HESE program. These projects are funded by grants $(\$ 12 \mathrm{~K}-$ $\$ 500 \mathrm{~K}$ ) from Venture Well (formerly NCIIA), EPA, USAID, Clinton Global Initiative and other sources.

HESE students are concurrently engaged in original publishable research in a wide swath of topics. Since 2009, over 80 scholarly articles have been published in peer-reviewed journals and conference proceedings, most of them with students as lead authors. While half of HESE students are engineers, the rest represent every other college across campus. Women constitute over $50 \%$ of the participants - a remarkable number for engineering and entrepreneurship, both of which suffer from poor gender equity. For most students, their experience with HESE is transformational as it exposes them to situations, opportunities and career paths they had never imagined. Over two-thirds of HESE students pursue medical school or graduate school. HESE students are pursuing an extremely wide range of non-traditional career paths from social 
ventures (e.g. low-cost feminine hygiene products) to repairing obstetric fistulas to improving rural supply chains to consulting with World Food Program and USAID.

\title{
Lessons Learned
}

While HESE courses are "institutionalized," the ventures and partnerships are independent, dynamic, organic and emergent. The HESE program has carefully documented and published the pedagogies, design tools, methodologies, technologies and outcomes for all courses and most ventures. All the course materials, including Powerpoint slides and video clips, are available on public websites. While several academic programs and student clubs work with communities, five things that set HESE apart are 1) extremely multi-disciplinary student and faculty teams, 2) emphasis on sustainable and scalable solutions, 3) a market-centric implementation approach, 4) integration of scholarly research, and 5) focus on execution - getting the job done in the field. The emphasis on execution and sustainable impact continue to strengthen over time. While most faculty and administrators view HESE as a mechanism to develop soft skills (and meet ABET outcomes), that is not the raison d'être of the program. HESE exists, and strives, to address global development challenges while preparing a cadre of social innovators and international development professionals. While we prioritize the socio-economic impact of our ventures, and the scholarly publications are essential, ultimately our students are the most important products because they can collectively transform this exciting field into a rigorous, vibrant, and respected global community of engaged scholars and problem-solvers...that deliver impact.

\section{Sustainability Leadership Minor}

\author{
Dr. Susannah Barsom, Director
}

\section{Introduction}

In 2012, The Pennsylvania State University introduced an intercollege minor in Sustainability Leadership. The minor is available to students in all majors, and a wide range of sustainabilityrelated courses is available to students wishing to complete this curriculum.

\section{Curriculum}

The 18-credit minor includes a required introductory course on leadership in sustainability and five additional sustainability courses of the student's choice: three chosen from all of the University's sustainability courses: one course with an immersive experience in sustainability, and a capstone course that focuses on a project addressing a real-world issue through approaches to sustainability leadership. Engineering students may focus on an engineering problem and solution for their immersive experience and/or capstone project, or they may choose to explore a non-engineering topic in completing the sustainability leadership curriculum. 


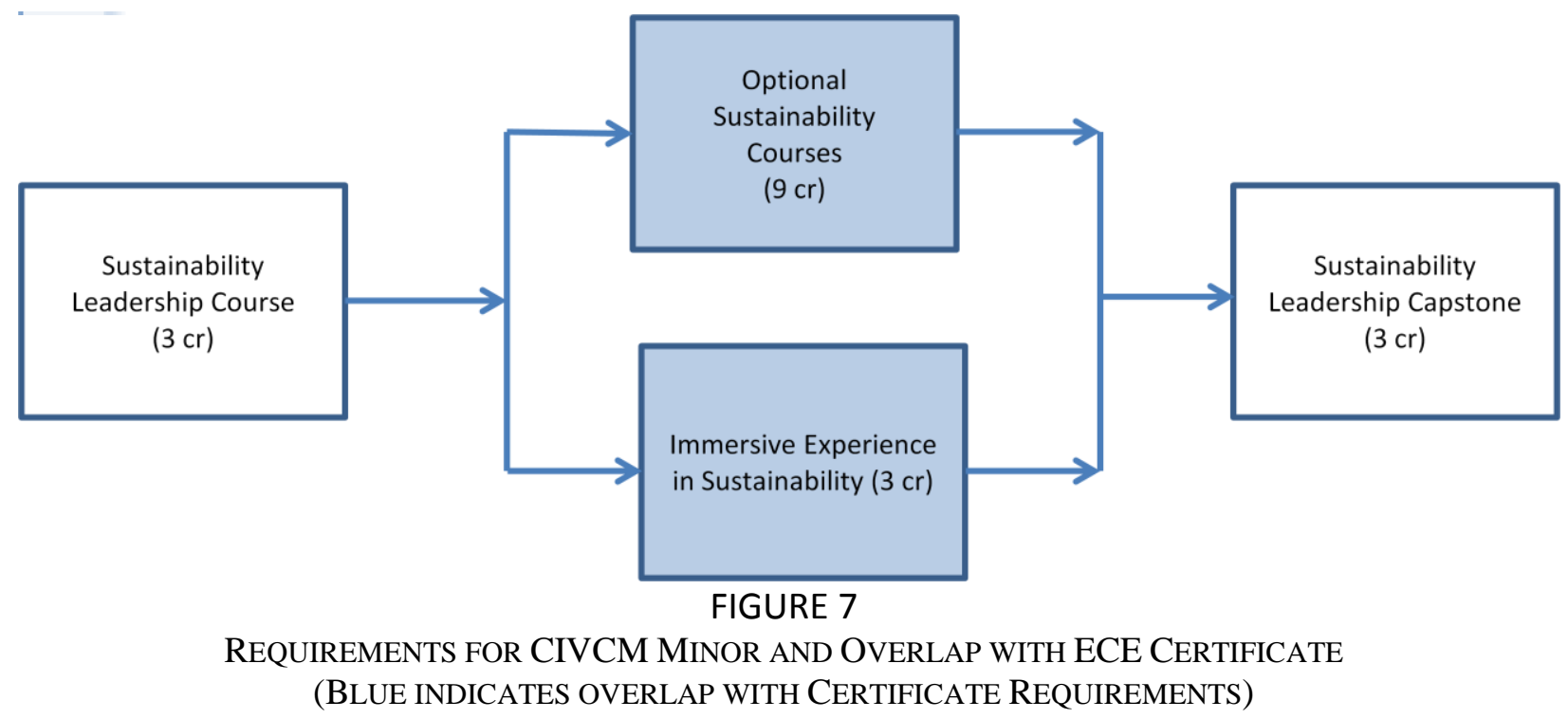

One of the advantages of this minor for many engineering students is the opportunity to interact with students in other majors. In the small introductory course, for example, there are always students from at least six different colleges, and assignments require students to work in teams, across disciplines. In many of the other classes that students take for this minor, there are class discussions and class assignments that reflect a broad range of approaches to sustainability issues.

Another benefit for students in the sustainability leadership minor is the passion that students in the minor bring to this work. The students in this program all care deeply about sustainability issues and want to bring positive change to the world. While many of us fondly remember college as a halcyon time of idealism and sincerity, we probably did have to seek out people who shared our visions of the future. The minor in sustainability leadership brings together people who have a common notion of what they'd like the world to be.

\section{Review to date}

Interest in the sustainability leadership minor has been growing rapidly. The program had around 25 students in the first year and 70 in its second year. The program is too new to understand the full implications of the minor. We have anecdotal evidence that students have received job offers in part because of their experiences in the minor. The capstone projects in particular have been of generally high quality and have given students the opportunity to engage deeply in real-world sustainability issues.

In the second year of the program, it was suggested that the breadth of sustainability courses available at the University was producing some minor curricula that were scattered and unfocused. The University's Office of Undergraduate Education requested a revision to the minor that created thematic tracks from which students could choose. The intention is to ensure a more concentrated study of some aspect of sustainability, such as food systems, community planning, education, renewable energy, etc. This version of the minor is under review and will be available to students by spring of 2015 .

The courses that so far seem to be most impactful are the immersive experience in 
sustainability and the capstone course. The options for an immersive experience cross several colleges and generally offer a safe and somewhat controlled experience in urban, rural, and wilderness experiences in the US and abroad. These courses provide the opportunity to engage in real world problems and in some ways serve as preparation for the independent work required in the capstone.

\title{
Case Studies
}

Student capstone projects have ranged from work in on agricultural issues in Central America to solving waste diversion problems on our own campus. One example from closer to home is a capstone project of a Biological Engineering student. This student analyzed the University's proposed plan to rebuild their water treatment facilities. She learned about both the University and the regional water treatment systems, and found that the region had excess capacity that might solve the University's problem. From that point, she met with key decision makers in both systems to discuss opportunities for cooperation; created a video proposing that rather than spend money and energy on rebuilding, the University should make use of the community's water treatment facilities; shared the video in public fora; and brought together several of the aforementioned key decision makers in meetings with the public to discuss proposed actions and best use of resources.

In the course of her capstone work, this student learned as much about the complexities of water treatment - in engineering terms and in political terms - as she might have in a job with a water authority. In bringing together the varied stakeholders with an interest in the issue, her efforts extended well beyond those of many beginning engineers. While the student has graduated, the discussion continues. Through her singular efforts, she raised the level of public discourse about options for water treatment in this community.

\section{Civic \& Community Engagement Minor (CIVCM)}

\author{
Dr. Theodore Alter, Program Head
}

\section{Introduction}

The Intercollege Minor in Civic and Community Engagement (CIVCM) empowers students to use classroom learning with and for communities. The CIVCM minor provides an opportunity for students to extend their education beyond the classroom through engagement in socially meaningful public scholarship in both pre-existing and newly developing community projects.

Students apply, test, analyze and re-formulate academic material in the context of public issues and community settings. Engaging in "learning-by-doing" allows students to communicate across differences, fulfill civic responsibilities, gain insight into personal values and world-views, develop civic skills including observation and listening, and further develop career interests and professional goals.

The Civic and Community Engagement Minor offers students agency to bridge classroom learning with actually existing public problems, thus helping to fulfill the Land Grant mission for both student-citizens and communities across the Commonwealth, the United States, and beyond. 


\section{Requirements}

The CIVCM curriculum allows flexibility to develop an academic plan according to the student's personal, professional, and academic interests. The program requires 18 credits of coursework as follows in Figure 7:

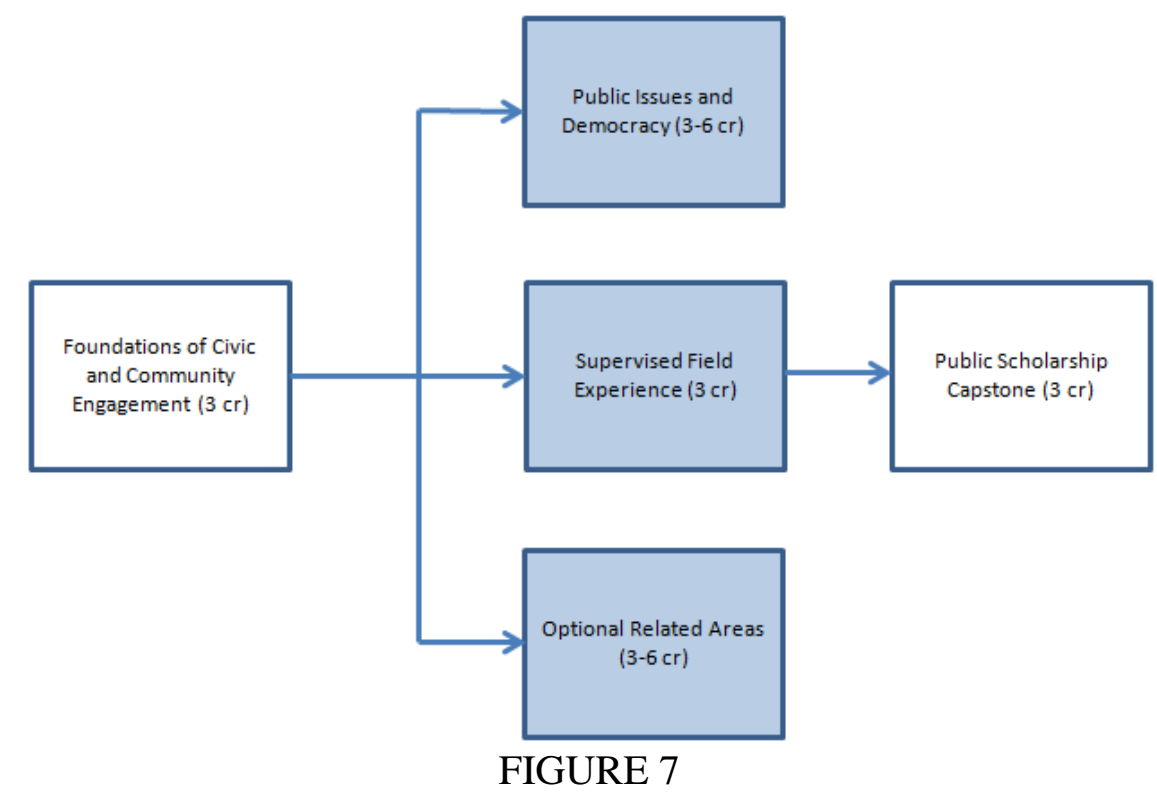

REQUIREMENTS FOR CIVCM MINOR AND OVERLAP WITH ECE CERTIFICATE (BLUE INDICATES OVERLAP WITH CERTIFICATE REQUIREMENTS)

The supervised field experience should consist of a sustained involvement in teaching and research related to important issues in the lives of people both within the campus environment and beyond. It includes regular contact with a faculty member to facilitate the integration of academic content with the fieldwork experience.

The public Issues and democracy courses investigate how academic disciplines may contribute to public debate and participation in civic issues and community problem solving. Through the lens of specific academic disciplines, and the examination of their civic meaning and public purpose, these courses contribute to student understanding of problems in and of democracy and the reciprocal relationships between academic and democratic practices. The purpose of these courses is to demonstrate how students may apply disciplinary knowledge in real-world contexts. The related areas course(s) are electives, selected to meet the student's specific learning goals.

The public scholarship capstone requires students to integrate the coursework, fieldwork, and research they have completed as undergraduates. Students are asked to demonstrate reflective analysis and substantial synthesis of their academic and field experiences in the Civic and Community Engagement Minor and to relate their work to the broader context of public scholarship and relevant societal issues. The required capstone project may be a thesis, annotated portfolio, or other original scholarly or creative work, which includes reflective thinking from a substantial out-of-the-classroom-walls learning experience. Public presentation of the capstone project is also required; this requirement might be fulfilled by a poster at the Undergraduate Exhibition, an online portfolio, a class presentation, or some other presentation suitable to a student's field of study. 


\title{
Engineering and Community Engagement Certificate
}

\section{Introduction}

\author{
Dr. Thomas Colledge, PE, Coordinator
}

The certificate in Engineering and Community Engagement (ECE) was developed to acknowledge students who have gained proficiency in design, leadership, entrepreneurship and/or service while collaborating with communities in the U.S. and abroad. Awareness of the cultural and ethical considerations when working in community settings is strongly stressed. Longer term, sustainable partnerships with communities are strongly encouraged. The certificate may serve as a pathway to a number of minors (see Figure 8), including:
a. Engineering Leadership Development Minor
b. Intercollege Entrepreneurship and Innovation Minor - Social Entrepreneurship Concentration, Humanitarian Engineering and Social Entrepreneurship Emphasis
c. Civic and Community Engagement minor
d. Sustainability Leadership minor.

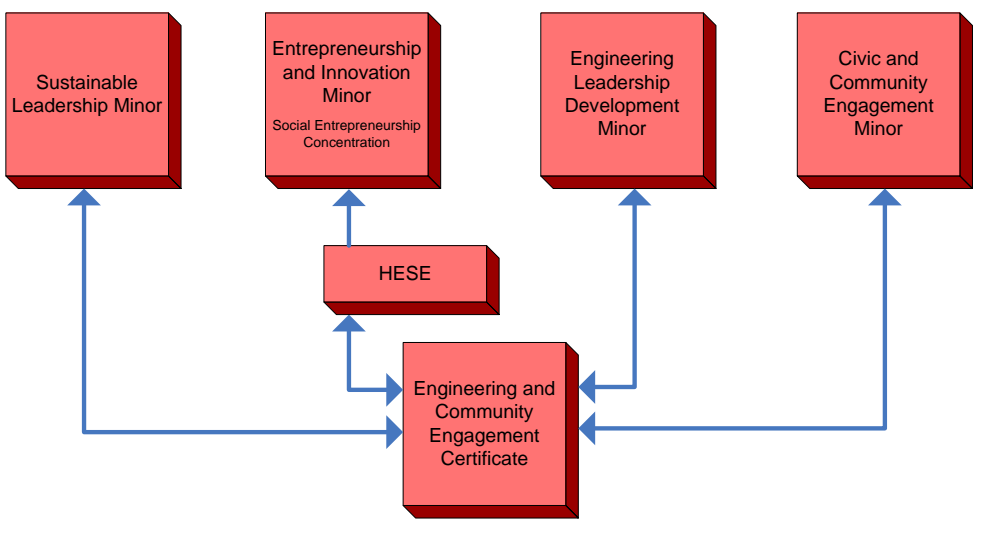

FIGURE 8

PATHWAY TO MinORS VIA THE ECE CERTIFICATE

\section{Background \& History}

The ECE Certificate was developed over a three year period between 2004 and 2007. Meticulous effort was taken to ensure that the certificate was flexible enough to encompass the needs and interests of students whether they be related to projects in: leadership, entrepreneurship, design and/or service. Close coordination and collaboration was undertaken between the various existing programs in the School of Engineering Design, Technology and Professional (SEDTAPP) programs to achieve the flexibility to accommodate the diverse interests of the students.

The curricular components consist of four courses (12 credits) and are listed below:

- Community Engagement $(3 \mathrm{cr})$

- Community-Based Design Project $(3 \mathrm{cr})$

- U.S./International Cultures (3 cr)

- Elective (leadership, entrepreneurship, service, design) $(3 \mathrm{cr})$ 
Such an adaptable set of required courses allows for the dovetailing of many of these courses into the various minors identified above. The requirements for each minor that may be satisfied by the certificate courses are highlighted in orange in Figure 9.

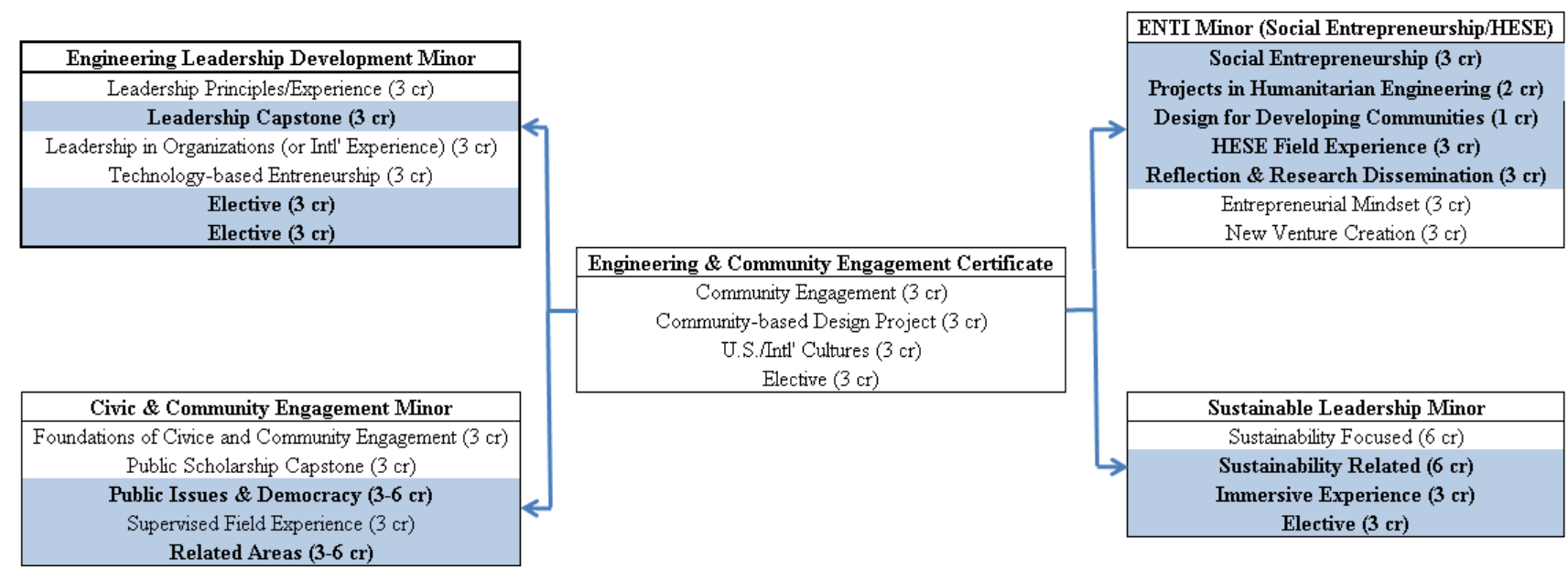

FIGURE 9

CERTIFICATE COURSEWORK Which SATISFIES MinOR REQUiREMENTS

\title{
Learning Factory Capstone Design
}

\author{
Dr. Mary Frecker, Director
}

Begun at Penn State in 1994, the Learning Factory brings the real-world into the classroom by providing engineering students with practical hands-on experience through industry-sponsored and client-based capstone design projects. The Learning Factory at Penn State is a universityindustry partnership established to integrate design, manufacturing and business realities into the engineering curriculum. This is accomplished by providing real (industry- driven) projects, a curriculum in Product Realization, and a state-of-the-art, hands-on learning laboratory. The Learning Factory began in 1994 as the result of a NSF/ARPA grant from the Technology Reinvestment Program. It has continued to grow and prosper long after the initial grant ended. In ten years of operation, the Learning Factory at Penn State has generated over $\$ 5 \mathrm{M}$ to support hands-on learning activities and projects, facilitated over 400 inter-disciplinary capstone design projects for 120 corporations and non-profit institutions, and provided real-world educational experiences for over 8,000 students. 


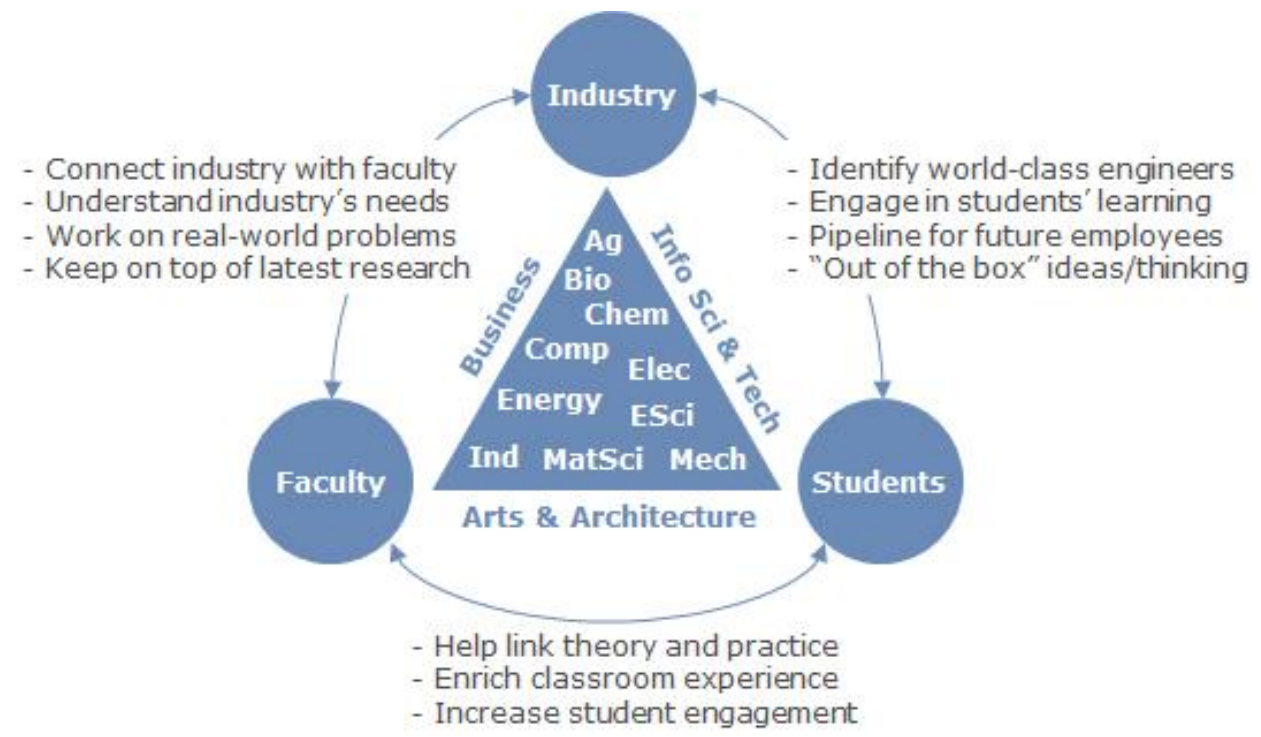

FIGURE 10

LEARNING FACTORY MODEL

The fundamental innovations of the Learning Factory that have had the greatest impact at Penn State are:

- Facilities: The Learning Factory is an open-access, active learning laboratory, where students, faculty and industry from all disciplines can "roll up their sleeves" and practice real engineering. It provides practical training and modern facilities for design, prototyping, manufacturing, testing and re-design. These facilities support numerous student design projects and competitions, enabling faculty to integrate engineering practice into their courses.

- Industry Interaction: The Learning Factory provides an efficient infrastructure for actively involving industry in the educational process through capstone design projects, curriculum improvement, and engineers in the classroom.

- Curriculum: The Product Realization Minor comprises three elective courses that cover product dissection, concurrent engineering, and engineering entrepreneurship, in addition to required courses in manufacturing processes, quality control, and the capstone design course. The Minor averages ten students each year from IE, ME, EE, and Engr Sci and has served as the benchmark for several new minors within the College of Engineering, including minors in Leadership and Entrepreneurship. In this paper, we present details of these successes along with lessons learned from our experiences.

Projects involve one or more disciplines in engineering, but we also try to partner engineering students with students in Business, Information Sciences \& Technology (IST), and other fields when appropriate. Business students have helped create real business plans for some of our start-up and small business partners, and IST students have helped companies address ITrelated issues (e.g., data management, access, security) as part of these projects.

Teams of engineering students tackle problems sponsored by real industrial clients, challenging students to apply the knowledge and tools acquired during their undergraduate 
education to help solve real engineering problems. Since the inception of the Learning Factory in 1994, more than 1630 such projects have been completed involving more than 7500 students. The Learning Factory provides a unique opportunity for industry sponsors to partner with Penn State to help educate the next generation of World Class Engineers using state-of-the-art facilities for design, prototyping, and fabrication.

For small companies, these teams are their "engineering workforce" for the semester. For larger companies, these teams are helping develop new ideas or improving current practices, both of which can impact a company's bottom line. These projects are also great ways for companies to get to know students when looking for new employees and also to train junior-level engineers and managers by providing project management experience in a low cost, low risk, potentially high pay-off setting. These are just some of the benefits that our sponsors report.

\title{
CO-CURRICULAR EFFORTS
}

\section{Internships and Coops}

\author{
Rick McClintic, Director
}

The College of Engineering offers a Cooperative Education and Professional Internship Program for students hoping to gain real-world experience before they graduate. While not required for graduation, co-ops and internships provide the hands-on experience and industry connections that will enhance employment opportunities as well as job performance. In fact, more than 30 percent of graduating seniors said they found their full-time positions through their internships or co-ops. Internships can be related to current or intended fields of study. They are typically limited to one semester, although multiple internships with the same company is possible.

Co-ops are directly related to the major. They typically span three semesters with the same employer, alternating with semesters at Penn State. When completed with the co-op experience, one full year of career-related experience is had and course credit for three semesters of co-ops.

In 2011, the latest available statistics are as follows:

- $42.5 \%$ of students completed one internship

- $33.0 \%$ of students completed two internships

- $24.5 \%$ of students completed three or more internships

- $45.2 \%$ of students who completed an internship received an offer for full-time employment from their internship employer

- $8.6 \%$ of students completed a cooperative education experience

- $54.4 \%$ of students who completed a cooperative education experience received an offer for full-time employment from their co-op employer 


\title{
Engineering Projects in Community Service (EPICS)
}

Timothy Wheeler, Faculty Adviser

EPICS (Engineering Projects In Community Service) at Penn State began in Spring 2001. The student group seeks students to lead extra-curricular efforts with an explicit intention to develop a service mentality while focusing on the development of engineering professionalism. Through EPICS, the specific problem (and need for a solution) is identified by local non-profit organizations. Based on the problem, an EPICS team designs, builds, and delivers a working solution to the non-profit group.

\section{American Indian Housing Initiative (AIHI)}

\author{
Dr. David Riley, Faculty Adviser
}

\section{Introduction}

The American Indian Housing Initiative is a collaborative effort to adapt and deploy sustainable building technologies on American Indian reservations. AIHI partners seek an educational exchange of cultural values and sustainable building technologies through collaborative and interdisciplinary partnerships. The challenges facing American Indian tribes are significant.

- On most American Indian reservations, 40 percent of homes are overcrowded and have serious physical deficiencies- 6 times the national average.

- The poverty rate for rural American Indians is $37 \%$ - three times higher than rural white communities, and the highest of any ethnic group.

- The National American Indian Housing Council (NAIHC) estimates that 200,000 housing units are needed immediately in Indian Country to provide adequate housing.

\section{Background}

Founded in 1998 at the University of Washington, the American Indian Housing Initiative is a sustained effort by university partners to address the housing crisis facing American Indians. Currently based at Penn State University, AIHI programs integrate courses, research, and outreach activities to foster mutually beneficial partnerships between universities and tribal organizations.

Initially providing design services, technical assistance, and on-site leadership to non-profit organizations such as the Red Feather Development Group, and the Kelly Foundation, AIHI now assists tribes to develop projects in a turnkey approach, assisting tribal groups with fundraising, and providing start-to-finish design, engineering, and project management of homes and community facilities.

To date, AIHI partners have constructed seven projects across the Northern Plains, including four homes, an adult education center, a community center, and a courtyard. Each project has contributed to the growing interest of tribes in the use of strawbale and other sustainable building technologies. 


\section{Objectives}

- Promote the study and deployment of green building technologies as energy-efficient, durable community-built housing solutions for tribal partners and the global community.

- Provide culturally enriching and applied experiences for students in various disciplines including engineering, architecture, and landscape architecture.

- Collaborate with American Indian Communities in the creation of capacity-building sustainable development strategies and outreach projects

\section{Integrating Research, Education and Service}

Students from various disciplines take part in research and analysis as a part of AIHI courses. This research is directly applied on AIHI projects, which provide valuable contributions to the advancement of sustainable technologies, and at the same time, provide much needed facilities on the Northern Cheyenne reservation. The AIHI projects utilize strawbale construction as the primary building component. There are many environmental and economic benefits to straw construction, but more importantly, the simplicity of the process allows people with little building experience to play a vital role in the construction process.

There is a three phase implementation strategy employed on all projects. These are:

Phase 1: Introduction, conception, and planning

Phase 2: Building relationships and infrastructure (in progress)

Phase 3: Develop sustainable and appropriate housing solutions

AIHI projects are designed, planned, and built by students, faculty, and AIHI collaborators. To date, the completed projects include four homes, an adult education center, an early childhood learning center, a technology center, several small scale testing and research buildings and a home for visiting faculty to Chief Dull Knife College, MorningStar MT. MorningStar MT was built in 2007 by the Penn State Solar Decathlon Team. This all-solar powered home is based on the design used by the team for their 4th place entry to the Solar Decathlon. The 1,000 sq foot strawbale residence consists of a prefabricated technical core and a site build living area.

AIHI facilitates annual courses (for Penn State students) and summer workshops in Lame Deer, MT (for students and volunteers). A 3-part course series at Penn State examines how sustainable building methods and technologies and residential energy efficiency assessments can be utilized to improve the living conditions common on American Indian reservations.

Part 1 (Spring): Students examine the physical and cultural context in which green building technologies and residential energy efficiency may be utilized.

Part 2 (Summer): Students spend 2 weeks in Montana participating in community-based sustainable construction projects and culturally immersive experiences offered by Chief Dull Knife College. Volunteers may spend 1 or 2 weeks.

Part 3 (Fall): Students document and reflect upon their experiences in order to assess the project and provide constructive recommendations for improvement of the AIHI course, project and program. A short presentation is prepared by the class and given to prospective students for recruitment and informational purposes. 


\title{
Partners
}

The work of AIHI is the result of strategic partnerships within Penn State and with other Universities. In addition, AIHI has developed a special partnership with the Northern Cheyenne Tribe.

- Chief Dull Knife College

- Northern Cheyenne Tribal Housing Authority

- UW_Madison Department of Landscape Architecture

\section{National Energy Leadership Corps (NELC)}

\author{
Dr. David Riley, Faculty Adviser
}

\section{Introduction}

The National Energy Leadership Corps (NELC) is an education and research program aimed at the transformation of how students and homeowners think and act regarding energy decisions in homes and other buildings. The NELC is designed to provide a systematic and scalable approach to a key challenge: the significant amount of energy wasted in homes that have been built with little or no regard to energy efficiency coupled with the significant shortage of energy literate citizens and professionals who are qualified to address this tremendous energy saving and economic development opportunity. Students gain the knowledge, skills, and professional attributes to conduct in-home energy assessments in a flipped classroom environment that includes extensive online learning resources coupled with practical and hands-on training during course meeting times. Custom designed tools support the processes of data collection and report preparation to quickly enable students to make useful contributions to homeowners in the form of advice and encouragement to take action in their homes. The culminating course experience results in small teams of students conducting energy assessments in their community that provide valuable experience for the students while also delivering value to homeowners. At the conclusion of the course, students are invited to continue performing assessment as interns, and also become mentors for students in future offerings of the course.

\section{History}

The NELC was conceived in 2008 by a team of industry and academic leaders seeking to create a scalable program that engaged students in home energy assessments. The initial design of the program was used to conduct multiple pilot courses and establish a proof-of-concept for the NELC. These results were used to solicit research funding and investor support to build an education and support infrastructure that was informed by state-of-the-art research and that could be shared by instructors nationwide to enable the scalability of the NELC program. In 2010 the NELC was awarded a contract from the U.S. Department of Energy (DOE) Building America program to experiment with alternative methods and procedures for energy auditing. That same year, the NELC was awarded funding from the BNY Melon Foundation to support the development of sharable learning resources and tools in addition to a portability demonstration project resulting in the adoption of the NELC at the University of Pittsburgh. In 2011, the NELC program was adopted as the foundation of a multi-tiered energy efficiency education strategy under development by the DOE Consortium for Building energy Innovation. Currently, the curriculum modules and support tools are being used by faculty volunteers in multiple demographics and climactic regions to further test portability and scalability of the NELC approach. 


\section{Assessment}

The NELC course and program is designed to cultivate an aggressive set of learning outcomes and is targeted at engineering students interested in developing leadership skills that help advance sustainability. Non-engineering students have also participated in the course and provided diversity in perspective and skills that have been found highly valuable to course activities and discussion. The core NELC educational objectives are to cultivate the ability of students to:

- Describe the challenges and strategies of engaging homeowners in home energy efficiency and the motivation of homeowners to act on energy efficiency improvement opportunities

- Demonstrate fundamental knowledge of home energy efficiency topics and residential construction methods affecting energy performance

- Develop inquiry skills that enable the objective and critical evaluation of energy efficiency technologies and strategies

- Gain experience in the systematic collection and diagnosis of situational conditions affecting the energy performance of homes

- Learn the fundamentals of home energy economics that are essential to a sustainable home energy future

- Gain the skills to engage homeowners in a meaningful assessment of their home and help them set actionable goals.

- Obtain capability to prepare a home energy profile customized to the conditions of a specific home and the priorities, concerns, and worldview of homeowners

Four methods are used to assess the progress of students toward these outcomes and importantly, provide constructive feedback leading to the development of efficacy as a capable leader. Knowledge of challenges and fundamental understanding of home energy systems is assessed through formative assessments embedded in online learning modules as well as written responses to reflective discussion topics. The development of technical skills such as the use of diagnostic equipment and ability to recognize and capture pertinent data are assessed through participation by students in class activities and summary presentations made by students to their peers. Students are then observed in the applied context of an actual home energy assessment and provided feedback on their performance and their success in identifying key priorities of homeowners and physical conditions of homes. Finally, the ability of students to synthesize the experience and produce a compelling set of recommendations is assessed through the evaluation of student reports as well as feedback from the homeowners.

\section{Lessons Learned}

Many valuable lessons have been derived from the development of the NELC in pilot course offerings as well as the evaluation of the program by a peer institution. Key lessons relevant to the adaption and growth of the NELC include:

- Students can develop efficacy as home energy assessors: As measured in the reports produced by homeowners and feedback from homeowners, NELC course participants have demonstrated the competence and confidence to complete home energy assessments 
in their communities that are perceived as highly valuable to homeowners based on post assessment evaluations of homeowners.

- Flipped classroom delivery results in opportunity for practice and team building during class meetings: The use of online modules to displace lectures and allow for more active learning settings was evaluated through formative learning assessments and focus group and demonstrated measurable improvements in student gains compared to early lecturebased versions of the class.

- Research-based tools are key to efficiencies in report authoring: An early barrier to the NELC process was the time and skill required for students to author a home energy assessment report. An online tool created to assist in writing reports was found to reduce the time to create a draft report by $51 \%$ and the time required to edit the report by $84 \%$ and a net reduction from an average of 7.2 hours/report to 2.3 hours/report.

- Portability of NELC: NELC program has been adopted by two universities as a technique to expand student engagement and expand sustainability-focused experiences for students. Each of these early adopters plans to continue or expand the use of the NELC as permanent programming.

\section{Case Study: Adoption of the NELC at the University of Pittsburgh}

In 2012 the NELC program was adapted to serve as the main course project in a graduate course in Design for the Environment. This effort initially served to evaluate the NELC concept, online learning modules, and in-class activities and resulted in valuable feedback and program upgrades. The initial success lead to a repeat offering of the course at the university of Pittsburgh followed by a summer internship program that resulted in 50 assessments completed by a team of five student leaders. In addition, the course practicum experiences were adapted to serve students with variable technical and communication skills and provide a model for how the NELC can serve interdisciplinary student audiences. The NELC has since been adapted in as a permanent feature of an undergraduate course in the Civil and Environmental Engineering Department at the University of Pittsburgh, and serves as a valuable demonstration of the portability of the NELC approach.

\section{Engineering Ambassadors}

Dr. Karen Thole, Faculty Adviser; Melissa Marshall, Director;

Dr. Michael Alley; Christine Haas

\section{Introduction}

To solve today's engineering challenges, we need a wide range of solutions, which can be realized only by having enough engineers with diverse and strong technical backgrounds. The current enrollments in engineering are not diverse, especially among women, blacks, and Hispanics ${ }^{66}$. On a related issue, a recent survey of engineers in industry indicates a compelling need for engineers to have strong communication skills ${ }^{67}$.

To address these challenges, the College of Engineering at the Pennsylvania State University created the Engineering Ambassador Program: a professional development program for undergraduate engineering students with an outreach mission to middle and high schools. The development mission is to enrich the communication and leadership skills of engineering 
undergraduates through academic programs. The outreach mission of this Engineering Ambassador Program is to attract a diverse population of middle and high school students into engineering. In short, the Engineering Ambassador Program places the right messenger (engineering students with advanced presentation skills) with the right message (messages about engineering from Changing the Conversation ${ }^{68}$ ) in front of middle and high school students.

\section{Program History}

While numerous outreach programs already exist at many institutions, what distinguishes the Engineering Ambassador Program is the communications training required for the undergraduate engineering students that prepare them for their high school visits. All students at Penn State must enroll in a general speech communications course; however, special sections of this course are offered to engineering students to prepare the students to give technical presentations. Those that excel in this course are invited to compete for the coveted position of being an Engineering Ambassador (generally 25 new Engineering Ambassadors are accepted each year into the program with well over three times as many who apply for the program). Those chosen to be Engineering Ambassadors then enroll in an advanced engineering communications course to prepare the students for their high school visits. The method of presentation used is an assertionevidence style ${ }^{69}$.

In the past four years, the engineering ambassador ${ }^{*}$ presentations have received much praise, both from the 10,000 middle and high school students visited and from those students' teachers. Correspondingly, the Program at Penn State has grown in the past four years from 12 female ambassadors to 66 ambassadors, of whom more than two-thirds are from groups underrepresented in engineering. Because of industry support, the program has spread to a network of three schools in the northeast in addition to Penn State: the University of Connecticut, Worcester Poly, and Rensselaer Poly. In August 2012, with an NSF workshop grant ${ }^{68}$, the Network held an inaugural national workshop that trained pilot programs of 2-4 engineering ambassadors at 17 other geographically diverse institutions with the goal of further expanding the Network. Based on the success of the workshop, NSF also funded a Type II TUES Grant to assist those institutions committed to creating an Engineering Ambassador Program. Workshops given by Penn State faculty and Engineering Ambassadors are taking place throughout the U.S. to train new Engineering Ambassadors at those institutions.

\section{Outcomes of the Engineering Ambassador Program at Penn State}

The Engineering Ambassador Program has several outcomes. The Program has created a strong student community in the College of Engineering, has provided additional professional development opportunities for the Engineering Ambassadors, and has helped to educate high school students and teachers on the contributions of engineering to the health, happiness, and safety of our world. Another outcome has been the national impact that the program has had on other institutions through the support of the National Science Foundation who granted Penn State resources to conduct engineering ambassador workshops at institutions across the U.S. In 2014, regional workshops were conducted at Vanderbilt University, San Jose State University, and Oregon State University. Over the next three years, similar regional workshops will be held to

\footnotetext{
* In this paper, the term engineering ambassadors will refer to engineering ambassadors of the Engineering Ambassador Network. A number of programs around the country carry the name "engineering ambassadors," but do not adhere to the principles that define the Engineering Ambassador Network.
} 
form an Engineering Ambassador Network. Despite entering the workshop with varying purposes for participation and experiencing varying degrees of small group integration during the workshop, all student attendees at the workshop reported that the workshop had been transformative for their professional communication skills.

\section{Lessons Learned}

What has worked well in forming the Engineering Ambassadors at Penn State is the community that this network has provided for our students, particularly our underrepresented students. So often, underrepresented groups are called upon to help recruit others similar to them; however, few tools are provided and too little benefit is given for taking on these time consuming service duties. We have found that students who become Engineering Ambassadors not only give but also receive. They receive the intense communications training needed to succeed in engineering and through the opportunities to practice these communication skills they receive increased confidence levels. Those students who have graduated and now gone into the world as successful professionals are using these skills and what they have learned about the right messages in describing engineering. Even beyond Penn State, there a numerous Engineering Ambassadors continuing their efforts in recruiting diverse students to engineering.

What has not worked so well is securing a sustainable, national network. There have been many discussions with a professional society with the hopes of integrating the Engineering Ambassador Network into their portfolio. For various reasons, however, this has not been an easy exercise to complete. Work will continue in securing sustainability for the Engineering Ambassador Network.

\section{International Journal for Service Learning, Humanitarian Engineering and Social Entrepreneurship (IJSLE)}

\section{Introduction}

Dr. Thomas Colledge, PE, Editor-in-Chief

Efforts to create the International Journal for Service Learning in Engineering (IJSLE) began in the fall of 2004 with the first issue subsequently published spring of 2006. The two principal goals of the Journal were: a) to foster inquiry into rigorous engineering design, research and pedagogy and direct those efforts toward collaboratively addressing issues experienced by marginalized communities, and 2) to nurture service learning in engineering as a distinct body of scholarly knowledge and to facilitate community building amongst practitioners. Interested authors were strongly encouraged to examine the cultural appropriateness of their work, seek to collaborate with their community partners to develop economically and culturally sustainable solutions, and implement appropriate technologies in a pro-active sense. Focus was also placed on associated pedagogy and program development.

In the spring of 2009, IJSLE expanded the scope of its publications to include manuscripts in the closely aligned fields of humanitarian engineering and technology-based social entrepreneurship. With that, the journal's name was modified to the International Journal for Service Learning in Engineering: Humanitarian Engineering and Social Entrepreneurship (IJSLE).

The journal is currently published twice per year, with occasional special issues, and is offered at no cost to subscribers online at www.ijsle.org. It provides open access to its content 
on the principle that making research freely available to the public supports a greater global exchange of knowledge.

\title{
Background
}

The journal utilizes the Open Journal System (OJS) which is a journal management and publishing system and employs the LOCKSS (Lots of Copies Keeps Stuff Safe) archiving management software system to create a distributed archiving system among participating libraries and permits those libraries to create permanent archives of the journal for purposes of preservation and restoration. To ensure open access and dissemination to users around the world who might benefit from the publications, regardless of available funding resources, the journal uses the Creative Commons Attribution 3.0 License which permits one to copy, distribute and transmit the work with proper attribution. The journal is indexed with EBSCO (Academic Search Complete database, EDS Discovery Service, and EBSCO Engineering Collection: India database); ProQuest (ProQuest Engineering, ProQuest Environmental Science, ProQuest Natural Science Collection, ProQuest SciTech Collection, ProQuest Technology Collection); Cabell Directories, Directory of Open Access Journals (DOAJ), Ulrich Directories, and Google Scholar. Since its inception, the number of journal subscribers has grown to over 6000+.

\section{Impact}

To facilitate scholarly endeavors, IJSLE provides an outlet for faculty to publish work in these areas. The goal of IJSLE was to build and nurture a journal which serves the needs of a particular academic community; those researchers and practitioners who work in the areas engaged scholarship (service learning in engineering, humanitarian engineering and social entrepreneurship). This academic community is relatively new and the goal was to attain greater scholarly recognition and credibility.

\section{EXTRA-CURRICULAR Engineers Without Borders - Penn State}

\author{
Dr. Rachel A. Brennan, P.E., Faculty Advisor
}

\section{Background and History}

EWB-PSU has been a recognized chapter of EWB-USA since the spring of 2010. Local Projects and planning for Alternative Spring Break were initiated immediately. The first International Project was implemented in Baoma, Sierra Leone: assessment trips were taken in July 2010 and December 2011, with implementation (construction) performed and completed in May, 2012. A pre-assessment trip to Roatán, Honduras, is planned for March, 2015.

Other than the variety of opportunities for students to get involved, the main thing that sets EWB-PSU apart is its current affiliation with a new initiative by the College of Engineering to integrate teaching and research into service outreach projects. Although many chapters of Engineers Without Borders (EWB) focus solely on international projects, the Penn State chapter of EWB (EWB-PSU) routinely maintains three avenues for student involvement throughout the year: Local Projects; Alternative Spring Break service trips; and International Projects. These multiple and varied avenues for participation were implemented to build a sense of community within the club, to encourage students to become involved, and to give them a sense of accomplishment, even while waiting for international projects to gain momentum. The Local 
Projects and Alternative Spring Break service trips are organized strictly by the chapter, with no affiliation or funding by EWB-USA. As with travel by other philanthropic clubs, the Alternative Spring Break service trips are typically funded in part by the university.

- Local Projects include: creating exhibits and teaching lessons at a local children's science museum; hosting activities at a "family science night" at a local high school; and providing hands-on lessons on the design process for elementary and middle school students.

- Alternative Spring Break service trips are typically coordinated with the Fuller Center for Housing to remodel or build houses for deserving families, often following natural disasters (hurricanes, etc.). These trips are now so popular that the chapter sends two groups of students to two different locations each year. The most common destinations for these trips are in Louisiana, but sites in Georgia, New Jersey, and Missouri have also been assisted.

- International Projects for EWB-PSU have focused predominantly on the design and construction of a latrine for a church and school in Baoma, Sierra Leonne, Africa (2010 2014). The chapter is currently in the process of gaining approval to work in the Central American island community of Roatán, Honduras (hopefully to begin in 2015). The focus in Roatán will be to design and build ecological restoration technologies to treat raw wastewater that is being dumped into estuaries around the island and thereby protect the second largest coral reef on the planet.

\section{Outcomes}

The EWB-PSU chapter has grown tremendously since its inception in 2010, and the number of local and service projects has blossomed. The chapter successfully completed the installation of a latrine for the community in Baoma, Sierra Leone. Undergraduate students in leadership positions have successfully gone on to graduate school, industry, and consulting.

\section{Lessons Learned}

International Projects are often challenging due to communication difficulties with foreign community members. Local politics within the communities themselves are often difficult to anticipate and negotiate. It has been learned that it is best to work on a project that truly benefits members of an entire community rather than one person's personal interest, otherwise the rest of the community may begin to harbor jealousy and the success of future projects may be thwarted.

In addition, it is difficult to gain momentum on design projects without appropriate technical oversight. After the formation of the EWB-PSU chapter, the design of International Projects was traditionally performed by a continuously-changing group of volunteer students, with little or no training in the specific technology being implemented. While ultimately educational, the process was often frustrating and extremely slow-paced as students struggled to teach themselves engineering design principles. Although faculty advisors and local professional engineers were identified, they were typically not invited to become actively engaged until very late in the design process. A new program has been recently instituted to change this approach.

Beginning in Fall 2014, EWB-PSU has come under the wing of a Global Engineering Leadership Program (GELP) grant, sponsored by the College of Engineering and led by the chapter's faculty advisors. Under this program, undergraduate and graduate students in EWB- 
PSU are encouraged to take senior-level engineering courses taught by the chapter advisors which focus on the EWB International Project as a design component. Now equipped with appropriate technical training, students who have taken the course(s) have the tools necessary to educate and lead the rest of the chapter in finalizing designs for the target community. Furthermore, graduate students from the advisors' research groups are also encouraged to participate in EWB Projects, providing another source of expertise and leadership to the organization. Faculty advisors are actively and directly engaged with international community members even prior to the inception of the project, establishing relationships for sustainable, long-term collaboration. This new initiative is anticipated to result in continuous, efficient progress, and high-quality, robust design solutions for the targeted community.

\section{Engineers for a Sustainable World (ESW)}

Joshua Kessler, Club President; Andrew Lau, Faculty Adviser

\section{Introduction}

Engineers for a Sustainable World (ESW) is dedicated to preparing the next generation of engineers for careers that are increasingly focused around sustainability. The green energy industry is expected to more than quadruple its workforce by 2025 , requiring innovative and ambitious engineers to solve some of the world's most complex energy problems. Even outside of the green energy industry, $67 \%$ of businesses include sustainability in their mission and values, and $63 \%$ of companies are currently taking action to reduce energy consumption. Our organization is preparing students to meet the demand for sustainability-minded engineers with hands-on real world projects. Our hands-on approach provides students with a variety of readily applicable experiences, from raising and managing a budget, to researching electrical and mechanical systems in order to design and build a workable and useful solution to actual problems.

\section{Activities}

ESW provides a variety of activities for students to become involved in. Our projects range from very technical design, to hands-on welding and machining, to developing business models, to improving the sustainability of our school and local community. This range of experience is very unique to our club. Our projects also benefit real communities, both local and distant. In addition to our projects, we seek to develop a deeper understanding of the changing energy industry. We discuss sustainability related topics over dinner, learn about innovative new developments in the green energy industry, and travel to renewable energy facilities such as wind-farms and solar power plants.

\section{Projects}

Although a number of our projects are still in development, some have already had an impact, both locally and nationally. One of our projects is a bike generator that powers light bulbs. The generator has a switch to alternate between powering incandescent bulbs and LED bulbs. We use our bike generator as a demonstration of LED efficiency at local public schools, teaching students about the importance of switching to efficient bulbs. Another project called Apparatus X is a disaster relief vehicle can relocate to the site of a natural disaster and help rebuild damaged homes. Our fundraising campaign on the crowdfunding website Indiegogo received national 
media attention on MSNBC and Wired Magazine, and we received donations from 16 states and 3 countries. Although we are still completing the project, it will soon have a positive impact on disaster-stricken communities across the country. This project has not only helped our members develop technical skills, but has also served as a demonstration that with enough willpower, we can apply our skills in a way that benefits the world.

\section{Hurdles}

One of our biggest struggles has been finding devoted project managers to lead our projects. Engineering is a time-consuming major and leading one of our projects is a massive undertaking. Unfortunately, we have recently faced setbacks in several projects due to project managers stepping down. Due to this concern, we have decided to begin appointing two project managers for larger projects in order to distribute the workload. This approach will hopefully help us avoid future complications.

In addition, when students have to choose between classes or an extracurricular, they always (rightfully) choose class. This issue has been a problem for us in the past, as devoting substantial amounts of time to a project is difficult for many of our members. Therefore, we decided to attempt a new approach last semester: establishing a course for our largest project, Apparatus X. About a dozen students took the course, which was once a week and required each student to design and prototype one component of the project. The course was tremendously successful, spawning many new ideas, and creating a large group of students who were committed to seeing the completion of the project.

\section{Penn State Global Water Brigades}

Krista Liguori, Club Co-President; Dr. Michael Saunders, Faculty Adviser

\section{Introduction}

Global Brigades (GB) is an international, student-led sustainable development organization that works on projects in Panama, Nicaragua, Honduras, and Ghana on programs ranging from medical assistance to financial planning. The organization is split between Global Brigades Inc., the Global Brigades Association (GBA), and country-specific organizations in Honduras, Panama, Nicaragua, Ghana. Global Brigades Inc. was formed as a registered non-profit in the United States to support students in fundraising and travel efforts. The GBA was created to unite all of the international organizations and make larger decisions about the direction of the organization. In each of the four countries GB works, programming is directed and run by local staff who make final decisions about programmatic changes.

Global Water Brigades (GWB) is one chapter of the larger organization, focusing on access to water of both sufficient quality and quantity in rural communities throughout Honduras and Ghana. Student engagement begins on campus and continues throughout the 7 or 10-day trips the brigades make to Honduras or Ghana, respectively. Year-round advisors and program directors are employed in each country to maintain community relations, assess community needs, decide which community projects will be conducted, prepare for student brigades, and conduct follow-up assessments of each project. Student groups are assigned to one of the previously identified community projects. A water project takes around 5-10 student groups to complete, a process that can take multiple years.

\section{Program History}

In 2011, two students established Penn State's Water Brigade chapter. As a new club, GWB gained all the same benefits of being a student club at Penn State, including financial support and 
access to many university resources. Water Brigades has since thrived as their own club, often collaborating with each of the 10 other GB chapters at Penn State. Penn State Global Brigades has Medical, Dental, Public Health, Environmental, Human Rights, Business, Microfinance, Architecture, Engineering, and Water chapters.

\section{Background}

At Penn State, GWB is set up as a student club, working through student affairs to take advantage of the beneficial resources this pathway provides. Students apply to join a specific project for the coming year. Accepted students then join their fellow brigaders, usually around 15 students for a Water Brigade and 40 for a Medical Brigade, in project meetings. Project meetings are weekly or biweekly meetings that occur for about 8 weeks leading up to their departure. A project meeting provides trip leaders the opportunity to inform each brigader on the essential steps to take in order to travel, have students meet each other and begin forming friendships, and to disseminate the pre-brigade curriculum.

Pre-Brigade curriculum is designed to teach new brigaders about the country, context, and projects in the regions they will be working. Information includes general topics on water poverty, issues with poor water quality, and the systemic causes and effects of water scarcity. Brigaders learn how Global Brigades implements the Holistic Model - a plan that incorporates a multi-sectorial approach by combining each of GB's 10 chapters in one community. Brigade Leaders are past brigaders with experience in the host country and therefore tend to incorporate stories and experiences from their time abroad. Using pictures and videos allows students to understand more the conditions they will be living in on a brigade and the type of work they'll be doing.

\section{GWB-PSU Successes and Struggles}

Coming to college, many students plan to spend time abroad, and find the short-term of a water brigade to perfectly fit their busy schedules. This allows a regular pool of incoming students who are interested in going abroad and can be recruited into Water Brigades. Water Brigades tends to have a group of 30 students that come to regular meetings, while 20-30 students travel each year.

GWB-PSU has encountered a number of different issues. A first issue with students is a lack of commitment to GWB as a club. Many students are interested in traveling abroad with the organization and attempt to participate only in the mandatory meetings and events.

A second issue GWB-PSU faces all too often is low retention rates. After going on their first brigade, most students stop attending meetings and leave the club. A potential factor is a limited amount of local initiatives that actively engage students throughout the year. To combat this issue, local initiatives have recently been created that allow students to work on domestic projects that address our interests in social responsibility and environmental sustainability.

\section{Student \& Community Outcomes}

Global Brigades goal is to empower students and communities. By engaging students one-onone to not only understand issues related to extreme poverty, but to take steps towards improving those issues, GB creates more mindful and globalized professionals. On an Engineering Brigade, students actively participate in designing a gravity water system in one rural Honduran community. GWB-PSU engaged 20 students in 2014 to build two Household Rainwater Harvesters in one Ghanaian community. 


\section{Lessons Learned}

As additional chapters (Human Rights, Environmental, Microfinance, etc.) were added to the organization over time, they operated separately in the university organization of clubs (each club was a separate entity) as well in how students interacted on brigades (every brigade was specific to one project). Recently, the integration of all programs into the Holistic Model to create a systematic approach and understanding of development challenges is emphasized. The holistic model integrates each of the 10 chapters both in-country during brigade trips, as well as at universities. At Penn State, all 10 chapters are housed under the Camps Council, a leadership board that oversees the actions of each chapter and coordinates between them.

In an attempt to create more relevant involvement options for students who are unable to travel or want to stay involved after their brigade, the Local Initiative club was created. This recent addition to the Penn State GB family was in response to brigader feedback as well as the low retention rates. The Food Bank-Farming initiative has been successful in mobilizing several students from all different chapters at Penn State to get together and work on a project that benefits members of our own community.

\section{Bridges for Prosperity}

Thomas Skibinski, PE, Faculty Adviser

\section{Introduction}

Bridges to Prosperity is a nonprofit organization which seeks to build footbridges over impassable rivers in impoverished rural areas across the globe. Through construction of bridges, residents of these communities are provided with better access to healthcare, education, and economic market opportunities. To date, Bridges to Prosperity has built over 130 bridges in 16 countries, connecting 650,000 people to schools, doctors, and jobs. In addition to the actual implementation of bridges, Bridges to Prosperity educates impoverished communities on the methodologies of bridge design, construction, and maintenance, so the communities will have lifelong access to these essential needs. The Penn State chapter was founded in the spring of 2013 and is composed of a dedicated core of students from various majors. The club is supported by the school's Civil Engineering department.

\section{Background}

Bridges to Prosperity was founded in 2001 as a non-profit organization that "provides isolated communities with access to essential health care, education and economic opportunities by building footbridges over impassable rivers." This is accomplished by Bridges to Prosperity members designing and implementing footbridge solutions that will be safe for community members to use, viable given local resources and conditions, and replicable for use at multiple sites. Bridges to Prosperity is dedicated not just to the actual construction of footbridges, but also to education on how to construct them. By dispersing knowledge of footbridge construction, the organization aims to amplify the scale of its fight against rural isolation. To date, the organization has built 100 bridges in 14 countries, impacting one half million lives.

Bridges to Prosperity formally recognizes student chapters at universities across the United States. There are two programs through which these chapters can conduct their own bridge projects:

- Program Project - This serves as a one year training mechanism in which a student chapter is assigned a project site by Bridges to Prosperity. Throughout the process, the 
chapter receives direct support and guidance from Bridges to Prosperity, including a field technical mentor and subsidized bridge cost. This project prepares the chapter to manage a chapter project.

- Chapter Project - Student chapters are responsible for identifying their own project site, initiating contact with the community, and fundraising for the full cost of the bridge. Chapters assert more independent control over the project, but are still able to take advantage of Bridges to Prosperity technical resources and mentors, as well as the organization's non-profit fundraising status.

\section{Penn State Chapter of Bridges to Prosperity}

The Penn State Chapter of Bridges to Prosperity was founded in the spring of 2013 and approved shortly thereafter for a Program Project in the summer of 2014. The chapter's first bridge was constructed in a community called Membrillo, located in Cocle, Panama. In May - June of 2014, the team went to Caimital, Panama to complete the bridge project.

The chapter currently consists of approximately 30 dedicated student members and is led by 10 student officers, each of which is responsible for a specific aspect of either the bridge project or the chapter's day to day operation. Two experienced faculty advisors from the civil engineering department support and advise the group.

While civil engineering students take the lead in designing the bridges, the chapter is comprised of students from a wide variety of other disciplines, all of whom will have the opportunity to travel with the chapter on construction trips.

\section{Organizational Structure}

The Penn State Chapter of Bridges for Prosperity consists of four committees that meet on a weekly to biweekly basis. Each is responsible for managing and operating a core aspect of the bridge projects: fundraising, construction, design, and cultural relations. The fundraising committee oversees all fundraising activities, including corporate relations, grant proposals, and on-campus fundraising events. The construction committee is responsible for planning and supervising all aspects of construction, including coordinating material purchases, transferring the bridge design into a detailed build schedule, and training the rest of the chapter on construction techniques and safety protocols. This committee supervises all chapter members on site during the construction trip while simultaneously coordinating with local community members who will be assisting. The design committee is responsible for collecting and processing all site survey data and designing the bridge. Using the survey data, the committee will lay out the bridge profile in AutoCAD in order to determine the size of the anchors and the number of tiers. The committee obtains the necessary approvals on the final design both from Penn State faculty and Bridges to Prosperity Technical staff to ensure the viability and safety of the design. Lastly the cultural relations committee communicates throughout the year with the community in which the chapter will be working. This committee includes several members fluent in the native language to help assist in translation while on site. It is also responsible for planning travel logistics and preparing chapter members for life in a new cultural environment. As the Penn State chapter progresses to a Chapter Project, this committee will take the lead in locating a community and project site abroad.

In May of 2014, the club participated in the first trip to build a bridge through Bridges to Prosperity. A 75 meter long foot bridge was constructed in Caimital, Panama, near Cocle. 


\section{NEED FOR NURTURING AND INTEGRATING AN ECOSYSTEM}

Each of the described curricular, co-curricular and extra-curricular opportunities for Penn State students has been evolving and growing. Each has been successful in its own right. However, the independent development of each of these programs has resulted in each having: their own faculty champion(s), their own unique missions and goals, and a strong sense of independence with limited collaboration or coordination. This certainly provides both advantages and disadvantages for each of the stakeholders. There are areas of improvement which must be addressed to truly make the overall effort sustainable, optimize the academic performance of each, and benefit all of the collaborating partners. Paramount in this regard is the need to institutionalize the effort, bring to bear the resources, catalyze the synergies, and leverage economies of scale, in short - to institutionalize the 'ecosystem'. This includes overcoming some of the hurdles listed earlier: a) adequate logistical support, b) promotion and tenure support, c) appropriate teaching loads, team teaching support, and time commitments (teaching assistants), d) lack of collegiality and support structure for faculty, e) silos and limited interdisciplinary engagement, f) rigorous quantitative assessment of engagement, g) long term community champions and communication (access to university resources), and $\mathrm{h}$ ) institutional respect, buy-in and support.

The ecosystem should be developed in such a way as to ensure the following attributes: a) scalability, b) variable system boundaries, c) diversity of major functional groups d) productivity and resource cycling, e) dynamic responses to contextual perturbations, and f) coupled relationships between system and context. Part III details the Penn State journey to develop such an ecosystem.

\section{REFERENCES}

1 Edward F. Crawley, Johan Malmqvist, Sören Östlund, Doris R Brodeur, Kristina Edström. 2014.

Rethinking Engineering Education: The CDIO Approach. Springer International Publishing.

${ }^{60}$ Pearce, A.R. and McCoy, A.P. (2007). "Creating an Educational Ecosystem for Construction: A Model for Research, Teaching, and Outreach Integration and Synergy," Proceedings, Construction Research Congress, May 6-8, Grand Bahamas Island.

${ }^{66}$ Carnevale, A.P. and S.J. Rose (2011). The Undereducated American. Available at http://www9.georgetown.edu/grad/gppi/hpi/cew/pdfs/undereducatedamerican.pdf

67 American Society of Engineering Education (2009). Available at http://www.asee.org/papersand-publications/publications/college-profiles/2009-profile-engineering-statistics.pdf. Accessed October 1, 2011.

${ }^{68}$ ASME (2010). Vision 2030-Creating the Future of Mechanical Engineering Education. American Society of Mechanical Engineers. New York.

${ }^{69}$ Michael Alley (2013). The Craft of Scientific Presentations, $2^{\text {nd }}$ ed. New York: SpringerVerlag. 